\title{
Trimethoprim-sulfamethoxazole as de-escalation in ventilator-associated pneumonia: a cohort study subanalysis
}

\author{
Alessio Strazzulla ${ }^{1,2}$ (1) - Maria Concetta Postorino ${ }^{2} \cdot$ Tracie Youbong $^{2} \cdot$ Maxence Rouyer $^{2} \cdot$ Clara Flateau $^{2}$. \\ Catherine Chakvetadze ${ }^{2}$. Astrid de Pontfarcy ${ }^{2}$ - Aurelia Pitsch ${ }^{3} \cdot$ Sebastien Jochmans ${ }^{4} \cdot$ Nabil Belfeki ${ }^{1}$. \\ Mehran Monchi ${ }^{4}$. Sylvain Diamantis ${ }^{1,2}$
}

Received: 17 October 2020 / Accepted: 3 February 2021 / Published online: 24 February 2021

(C) The Author(s), under exclusive licence to Springer-Verlag GmbH, DE part of Springer Nature 2021

\begin{abstract}
Purpose This is a subanalysis of a previous study which compared the effectiveness of trimetoprim-sulfametoxazole (TMPSMX) with all other regimens for treatment of ventilator-associated pneumonia (VAP). Aim of the current study was to focus on the effectiveness of a strategy based on TMP-SMX as de-escalation from $\beta$-lactam including regimens.

Methods Retrospective cohort study including patients who were hospitalized for VAP from 2011 to 2019. Patients were distributed in two groups: NO SWITCH TO TMP-SMX group, including patients who received $\beta$-lactams for all treatment duration, and SWITCH TO TMP-SMX group, which included patients who switched to TMP-SMX from a $\beta$-lactam including regimen after microbiology diagnosis. Three clinical outcomes were analyzed: mortality at 30 days from the start of the antibiotic treatment (T30), mortality at the end of treatment (EoT), and acquisition of multidrug-resistant bacteria during hospitalization in intensive care unit.

Results Overall, 70 patients were included in the current study, 32/70 (45.7\%) in NO SWITCH TO TMP-SMX group and 38/70 (54.3\%) in SWITCH TO TMP-SMX group, 37/70 (52.8\%) had been already included in the previous study. No significant differences in clinical outcomes and patient's characteristics were found when the two groups were compared.

Conclusions De-escalation to TMP-SMX for VAP treatment was not associated with higher mortality at EoT and T30 than standard treatment with $\beta$-lactam. Monotherapy with TMP-SMX as de-escalation from broad-spectrum empirical regimens is a $\beta$-lactam sparing strategy worthy to be further investigated in either multicenter cohort studies or randomized clinical trials.
\end{abstract}

Keywords trimethoprim-sulfamethoxazole $\cdot$ ventilator-associated pneumonia $\cdot$ de-escalation $\cdot \beta$-lactam sparing strategy

The datasets used and/or analyzed during the current study are available from the corresponding author on reasonable request.

Alessio Strazzulla

alessio.strazzulla@ghsif.fr

1 Internal Medicine Unit, Groupe Hospitalier Sud Ile de France, Melun, France

2 Infectious Diseases Unit, Groupe Hospitalier Sud Ile de France, Melun, France

3 Medical Biology Laboratory, Groupe Hospitalier Sud Ile de France, Melun, France

4 Intensive Care Unit, Groupe Hospitalier Sud Ile de France, Melun, France

\section{Introduction}

$\beta$-lactam sparing strategies are strongly recommended to reduce the selection of extended spectrum $\beta$-lactamase (ESBL) and carbapenemase-producing bacteria [1]. Nevertheless, $\beta$ lactams are largely used for treatment of ventilator-associated pneumonia (VAP), as empirical treatment to cover potential infection sustained by gram negative bacilli. They are often associated with other molecules which cover methicillinresistant Staphylococcus aureus (MRSA), as recommended by international guidelines $[2,3]$. Broad-spectrum regimens are potentially not appropriate, and quick de-escalation is recommended when microbiology data are available to adapt treatment to antibiotic susceptibility [4]. Moreover, deescalation allows reducing broad-spectrum antibiotic use in intensive care unit (ICU), and it is not associated with increased mortality [5]. However, few data are available about 
the best molecules to use for targeted treatment of VAP, and no specific recommendations are given by international guidelines $[2,3]$.

Trimethoprim-sulfametoxazole or co-trimoxazole (TMPSMX) is usually active on the most frequent bacteria associated with VAP, notably S. aureus (including MRSA) and Gram negative bacilli (Enterobacteriaceae) with the exception of nonfermenting Gram negative bacilli, Pseudomonas aeruginosa, and Acinetobacter baumannii [6]. In a previous study, we demonstrated that treatment of VAP with TMPSMX was not associated with higher mortality and multidrug-resistant (MDR) bacteria acquisition than treatment not including TMP-SMX. However, that study compared patients receiving TMP-SMX, as first-line therapy or as de-escalation, with patients not receiving TMP-SMX treated with $\beta$-lactams or other broad-spectrum antibiotics, such as fluoroquinolones. That study did not focus on TMP-SMX as de-escalation from $\beta$-lactam including regimens for VAP treatment [7].

Aim of this study was to perform a subanalysis to verify the effectiveness of a de-escalation strategy from $\beta$-lactams to TMP-SMX for treatment of VAP.

\section{Materials and methods}

We conducted a monocentric retrospective cohort study in an ICU of a 350 acute-care-bed hospital in the Ile de France region in France. The entire cohort of patients identified in the previous study (2011-2017) plus all patients with a diagnosis of VAP from January 1, 2018, to December 31, 2019, were considered for inclusion [7]. From this new cohort, only patients with VAP treated with broad-spectrum penicillins plus/minus $\beta$-lactamase inhibitors as first-line regimen and who switched or not to TMP-SMX were included. Exclusion criteria were (i) absence of isolates at cultures from lower respiratory tract samples; (ii) positivity at cultures from lower respiratory tract samples for TMP-SMX naturally resistant bacteria ( $P$. aeruginosa and A. baumannii); (iii) positivity at cultures from lower respiratory tract samples for naturally $\beta$-lactam-resistant bacteria (Stenotrophomonas maltophilia); (iv) first-line treatment with molecules different from broadspectrum penicillins; (v) switch to alternative molecules to broad-spectrum penicillins and TMP-SMX.

The study was conducted in accordance with Declaration of Helsinki and national and institutional standards. Approval by the local ethic committee was not demanded because a noninterventional research was conducted, according to French law. A written consent form was not proposed to patients because the noninterventional nature of the study required only the absence of patients' opposition, according to the French law $[8,9]$.
VAP was defined as infection of pulmonary parenchyma developed after at least $48 \mathrm{~h}$ of mechanical ventilation [10]. For all patients, first-line treatment always included a broadspectrum penicillin plus/minus $\beta$-lactamase inhibitor (amoxicillin, piperacillin, amoxicillin/clavulanic acid and piperacillin/tazobactam). No antibiotic for MRSA coverage was systemically added because of the extremely low rate of MRSA in our hospital (5\%). De-escalation to TMP-SMX was systemically proposed when antibiotic susceptibility test for microbiologic isolates from lower respiratory tract samples was available not later than $48-72 \mathrm{~h}$ from the beginning of the antibiotic treatment. All patients with susceptible isolates switched to TMP-SMX, regardless of clinical response and even in case of clinical worsening. This decision was justified by the priority of limiting selection of ESBL. Patients continued or switched to broad-spectrum penicillin plus/minus $\beta$ lactamase inhibitor when antibiotic susceptibility test was not available at $48-72 \mathrm{~h}$ from the beginning of the antibiotic treatment or it documented TMP-SMX-resistant isolates. TMPSMX was prescribed at a maximal dose of $160 / 800 \mathrm{mg}$ tid or qid and adapted to estimated glomerular filtration rate (eGFR) and patient's weight [11]. All patients received a 7day-long antibiotic treatment, with broad-spectrum penicillins plus/minus $\beta$-lactamase inhibitors with or without switch to TMP-SMX.

Patients were retrospectively pooled in two groups: (i) NO SWITCH TO TMP-SMX group, which included patients who started a $\beta$-lactam as first-line treatment and maintained a $\beta$ lactam based regimen even after microbiologic diagnosis, and (ii) SWITCH TO TMP-SMX group, which included patients who switched to TMP-SMX from a $\beta$-lactam including regimen.

For collection of patients' characteristics, laboratory analysis and clinical outcomes, the following software were used: Sillage v17.2.4.5 and CGM Lab channel 1.20.33686. Patients' characteristics included age, gender, body mass index (BMI), co-morbidities, antibiotic treatment before the onset of VAP, simplified acute physiology score II (SAPS-II), early VAP, shock, bacteria isolates from lower respiratory tract samples, antibiotic susceptibility and first-line molecules. Comorbidities included diabetes, heart disease (acute myocardial infarcts and heart failure), lung disease (chronic obstructive pulmonary disease or chronic restrictive diseases), liver disease, solid or hematologic neoplasia, severe acute or chronic kidney disease. Severe kidney disease was defined for $\mathrm{eGFR}<30 \mathrm{ml} / \mathrm{min}$ [12]. An onset of VAP $\leq 96 \mathrm{~h}$ from the start of mechanical ventilation was considered for the definition of early VAP [13]. Shock was defined by the needing of vasopressors to maintain a mean arterial pressure $\geq 65 \mathrm{mmHg}$ at VAP onset [14].

All positive isolates from lower respiratory tract samples were considered (endotracheal aspiration or bronchoalveolar lavage). Bronchial secretions were analyzed when they 
presented $<25$ squamous epithelial cells and $>25$ leukocytes per low power field. Bacterial culture threshold was $10^{5}$ for endotracheal aspirate and $10^{4}$ for bronchoalveolar lavage.

Primary outcome was mortality at 30 days after antibiotic treatment initiation (T30). Secondary outcomes were (i) mortality at the end of treatment (EoT); (ii) acquisition of MDR bacteria during hospitalization in ICU; (iii) severe allergy occurrence (defined as any allergic event causing antibiotic treatment interruption or switch to other molecules); (iv) Clostridium difficile disease occurrence (defined as the presence of binary toxin in stools). Nasopharyngeal and rectal swabs were systemically realized at admission and discharge, and their results were considered for definition of MDR bacteria. Other samples obtained during the hospitalization according with patient's clinical evolution were also considered for definition of MDR acquisition. MDR research included MRSA, ESBL and carbapenemase-producing bacteria.

The two groups of patients were compared (NO SWITCH TO TMP-SMX vs. SWITCH TO TMP-SMX). The following statistic tests were performed: $\chi^{2}$ test for qualitative variables and Student's $t$ test for quantitative variables. Quantitative variables were presented in the text as mean values.

$R$, the language for statistical computing (Vienna, Austria, https://www.r-project.org/), was used to perform all statistical analysis. Nominal statistical significance was set at $p<0.050$.

\section{Results}

Overall, 199 cases of VAP were identified from January 1, 2011, to December 31, 2019. Among them, 126/199 (63.3\%) had been already identified for the previous study (20112017) while 73/199 (36.7\%) were newly detected (20182019). A total of $70 / 199$ (35\%) patients were included in the current study, among them, 37/70 (52.8\%) had been already included in the previous study. According to exclusion criteria, the following patients were excluded: 10/199 (5\%) patients had not microbiology diagnosis, 48/199 (24\%) patients had $P$. aeruginosa and Acinobacter baumannii isolates, 10/199 (5\%) patients had Stenotrophomonas maltophilia isolates, 52/199 (26\%) patients were excluded because their firstline treatment included molecules different than broadspectrum penicillins and 8/199 (4\%) patients were excluded because they switched towards a molecule different than TMP-SMX or broad-spectrum penicillins.

Overall, 32/70 (45.7\%) patients were included in NO SWITCH TO TMP-SMX group and 38/70 (54.3\%) in SWITCH TO TMP-SMX group. All patients started a monotherapy with a $\beta$-lactam as first-line treatment with the exception of two patients who started a dual therapy with piperacillin/tazobactam plus aerosolized amikacin and amoxicillin/clavulanic acid plus linezolid, respectively. The following $\beta$-lactam molecules were prescribed as first-line regimen: piperacillin/tazobactam $(34 / 70,48.6 \%)$, amoxicillin/clavulanic acid $(27 / 70,38.6 \%)$, amoxicillin $(7 / 70,10 \%)$ and piperacillin $(2 / 70,2.8 \%)$. Switching to another molecule was prescribed in $48 / 70(68.5 \%)$ as monotherapy $(45 / 48,93.7 \%)$ or dual therapy $(3 / 48,6.3 \%)$. The following $\beta$ lactams were prescribed for de-escalation in 10/48 $(20.8 \%)$ patients: amoxicillin/clavulanic acid (4/10, 40\%), piperacillin/tazobactam $(3 / 10,30 \%)$ and amoxicillin $(3 / 10$, $30 \%)$. Aerosolized amikacin was associated with $\beta$-lactams in $2 / 32(6.25 \%)$ patients. A total of $38 / 70(54.3 \%)$ patients switched to TMP-SMX. Among them, only one patient switched to a dual therapy with TMP-SMX and aerosolized amikacin $(1 / 38,2.6 \%)$ while the rest of patients switched to a monotherapy $(37 / 38,97.4 \%)$.

Comparison of NO SWITCH TO TMP-SMX and SWITCH TO TMP-SMX groups did not show any significant differences (Table 1) in terms of patient's characteristics and clinical outcomes (mortality at T30, mortality at EoT and acquisition of MDR bacteria). Analysis of safety profile showed no case of severe allergy in NO SWITCH TO TMP-SMX and SWITCH TO TMP-SMX groups. Clostridium difficile disease occurred only in a patient who switched to TMP/SMX from amoxicillin.

\section{Discussion}

Results of this study suggest that TMP-SMX may represent a valid alternative to $\beta$-lactams in case of VAP with microbiology diagnosis. Indeed, no differences were found in terms of clinical outcomes (mortality at T30 and EoT, and MDR bacteria acquisition) when NO SWITCH TO TMP-SMX and SWITCH TO TMP-SMX groups were compared. Because of lack of activity on nonfermenting Gram-negative bacteria ( $P$. aeruginosa and A. baumannii), the best use of TMP-SMX on VAP is likely de-escalation after microbiology diagnosis. First-line empirical treatment with TMP-SMX should be avoided.

Although quick de-escalation is recommended by international guidelines $[2,3]$, no study was performed to compare the effectiveness of different regimen for de-escalation treatment of VAP. This is the first study which analyses the effectiveness of de-escalation from a $\beta$-lactam regimen toward a regimen not including $\beta$-lactams.

De-escalation therapy for VAP should always been encouraged because it is associated with some advantages. At first, de-escalation reduces the exposition to $\beta$-lactamase inhibitor and carbapenems and the risk of selection of ESBL and carbapanemase producing bacteria $[15,16]$. Secondly, it allows reducing cost and duration of hospitalization without affecting clinical outcomes, notably mortality [17-20]. Third, it reduces the number of molecules administered, and consequently, it enhances the safety profile of antibiotic treatment [21]. 
Table 1 Characteristics of the population

\begin{tabular}{|c|c|c|c|}
\hline Parameters & $\begin{array}{l}\text { NO SWITCH TO } \\
\text { TMP-SMX } \\
(n=32)\end{array}$ & $\begin{array}{l}\text { SWITCH TO } \\
\text { TMP-SMX } \\
(n=38)\end{array}$ & $p$ value \\
\hline \multicolumn{4}{|l|}{ Biological parameters } \\
\hline Age years [mean $(\mathrm{SD})]$ & $60(17.6)$ & $66(11.8)$ & 0.06 \\
\hline Male gender $[n(\%)]$ & $27(84.4)$ & $29(76.3)$ & 0.40 \\
\hline BMI (SD) [mean (SD)] & $28.50(6.3)$ & $28.52(5.4)$ & 0.99 \\
\hline \multicolumn{4}{|l|}{ Co-morbidities } \\
\hline Diabetes $[n(\%)]$ & $8(25)$ & $16(42.1)$ & 0.13 \\
\hline Heart disease $[n(\%)]$ & $17(53.1)$ & $22(57.9)$ & 0.69 \\
\hline Lung disease $[n(\%)]$ & $13(40.6)$ & $12(31.6)$ & 0.43 \\
\hline Liver disease $[n(\%)]$ & $6(18.8)$ & $8(21.1)$ & 0.81 \\
\hline Cancer $^{\mathrm{a}}[n(\%)]$ & $6(18.8)$ & $5(13.2)$ & 0.52 \\
\hline $\mathrm{eGFR}<30 \mathrm{ml} / \mathrm{min}[n(\%)]$ & $4(12.5)$ & $7(18.4)$ & 0.50 \\
\hline \multicolumn{4}{|l|}{ Clinical parameters } \\
\hline SAPS-II [mean (SD)] & $47(19.5)$ & $49(16.7)$ & 0.65 \\
\hline Antibiotic treatment before VAP $[n(\%)]$ & $25(78.1)$ & $31(81.6)$ & 0.72 \\
\hline Early VAP $[n(\%)]$ & $8(25)$ & $15(39.5)$ & 0.20 \\
\hline Shock $[n(\%)]$ & $17(53.1)$ & $23(60.5)$ & 0.53 \\
\hline \multicolumn{4}{|l|}{ Bacterial isolates from lower respiratory tract samples } \\
\hline $\begin{array}{l}\text { Enterobacteriacae }[n(\%)] \\
\text { Haemophilus influenzae }[n(\%)]\end{array}$ & $\begin{array}{l}19(59) \\
6(19)\end{array}$ & $\begin{array}{l}32(84) \\
3(8)\end{array}$ & 0.14 \\
\hline Gram positive bacteria $[n(\%)]$ & $7(22)$ & $3(8)$ & \\
\hline \multicolumn{4}{|l|}{ Antibiotic susceptibility } \\
\hline Amoxicillin susceptible $[n(\%)]$ & $7(21.87)$ & $6(15.78)$ & 0.51 \\
\hline Amoxicillin/clavulanic acid susceptible $[n(\%)]$ & $23(71.87)$ & $12(31.57)$ & 0.0007 \\
\hline Piperacillin/tazobactam susceptible $[n(\%)]$ & $26(81.25)$ & $27(71.05)$ & 0.32 \\
\hline Third generation cephalosporin susceptible $[n(\%)]$ & $25(78.12)$ & $30(78.94)$ & 0.93 \\
\hline Fluoroquinolone susceptible $[n(\%)]$ & $24(75)$ & $36(94.73)$ & 0.02 \\
\hline TMP-SMX susceptible $[n(\%)]$ & $18(56.25)$ & $38(100)$ & $<0.0001$ \\
\hline \multicolumn{4}{|l|}{ First-line molecules } \\
\hline $\begin{array}{l}\text { Amoxicillin }[n(\%)] \\
\text { Amoxicillin/clavulanic acid }[n(\%)]\end{array}$ & $\begin{array}{l}5(16) \\
10(31)\end{array}$ & $\begin{array}{l}2(5) \\
17(45)\end{array}$ & 0.17 \\
\hline Piperacillin $[n(\%)]$ & $2(6)$ & $0(0.0)$ & \\
\hline Piperacillin/tazobactam $[n(\%)]$ & $15(47)$ & $19(50)$ & \\
\hline \multicolumn{4}{|l|}{ Clinical outcomes } \\
\hline EoT mortality $[n(\%)]$ & $6(18.8)$ & $9(23.7)$ & 0.62 \\
\hline T30 mortality $[n(\%)]$ & $12(37.5)$ & $16(42.1)$ & 0.69 \\
\hline MDR bacteria acquisition during hospitalization ${ }^{\mathrm{b}}[n(\%)]$ & $3(9.4)$ & $5(13.2)$ & 0.62 \\
\hline
\end{tabular}

BMI body mass index; eGFR estimated glomerular filtration rate; MDR multidrug-resistant; SAPS-II simplified acute physiology score II; SD standard deviation; TMP-SMX trimethoprim-sulfamethoxazole; VAP ventilatorassociated pneumonia

${ }^{\text {a }}$ Includes both solid and haematological cancer.

${ }^{\mathrm{b}}$ According to nasopharyngeal and rectal swab screening (at admission and discharge) and other samples obtained during the hospitalization.
This study is monocentric, and it is limited by retrospective design, small population and absence of sample size calculation. Consequently, results are not definitive and need to be reproduced in bigger studies. However, aim of this study was to perform an exploratory analysis which could justify new multicenter studies, either retrospective cohort studies or randomized clinical trials (RCT). In particular, RCT are strongly required because they represent the most suitable way to compare drug efficacy and effectiveness. We retain that for its pharmacodynamic and pharmacokinetic characteristics, 
TMP-SMX is worthy to be further explored as de-escalation treatment for VAP. Indeed, its higher lung concentration and intestinal absorption make it suitable for a quick and rapid switch from an intravenous treatment after microbiology diagnosis $[13,14,22]$. Moreover, its activity versus the most common agents of VAP, namely, Enterobacteriacae, MRSA and vancomycin intermediate or resistant $S$. aureus, makes it an interesting molecule even in settings with high prevalence of $\beta$-lactam and glycopeptide-resistant bacteria [23-25]. Further studies should investigate whether these theoretical benefits produce a clinical advantage or not. In particular the impact of de-escalation to TMP-SMX on clinical outcomes (mortality and MDR bacteria acquisition) should be defined.

In conclusion, this study reported encouraging results about the use of TMP-SMX as de-escalation for treatment of VAP. Monotherapy with TMP-SMX as de-escalation from broad-spectrum empirical regimes is a $\beta$-lactam sparing strategy worthy to be further investigated in either multicenter cohort studies or RCT.

Funding This study was carried out as part of routine work. Neither funding from privates nor research grants were received.

\section{Declarations}

Competing interest The authors declare no competing interests.

Ethical approval For this type of study, formal consent is not required.

Consent for publication Because this study did not require neither further laboratory analysis nor different clinical acts than daily clinical routine, a written consent form was not proposed to any eligible patients

\section{References}

1. Lesho EP, Laguio-Vila M (2019) The slow-motion catastrophe of antimicrobial resistance and practical interventions for all prescribers. Mayo Clin Proc 94(6):1040-1047. https://doi.org/10. 1016/j.mayocp.2018.11.005

2. Kalil AC, Metersky ML, Klompas M, Muscedere J, Sweeney DA, Palmer LB, Napolitano LM, O'Grady NP, Bartlett JG, Carratalà J, El Solh AA, Ewig S, Fey PD, File TM Jr, Restrepo MI, Roberts JA, Waterer GW, Cruse P, Knight SL, Brozek JL (2016) Management of adults with hospital-acquired and ventilator-associated pneumonia: 2016 Clinical Practice Guidelines by the Infectious Diseases Society of America and the American Thoracic Society. Clin Infect Dis 63(5):e61-e111. https://doi.org/10.1093/cid/ciw353

3. Torres A, Niederman MS, Chastre J, Ewig S, Fernandez-Vandellos P, Hanberger H, Kollef M, Li Bassi G, Luna CM, Martin-Loeches I, Paiva JA, Read RC, Rigau D, Timsit JF, Welte T, Wunderink R (2017) International ERS/ESICM/ESCMID/ALAT guidelines for the management of hospital-acquired pneumonia and ventilatorassociated pneumonia: guidelines for the management of hospitalacquired pneumonia (HAP)/ventilator-associated pneumonia (VAP) of the European Respiratory Society (ERS), European Society of Intensive Care Medicine (ESICM), European Society of Clinical Microbiology and Infectious Diseases (ESCMID) and Asociación Latino Americana del Tórax (ALAT). Eur Respir J 50(3):1700582. https://doi.org/10.1183/13993003.00582-2017

4. Erdem H, Cag Y, Gencer S, Uysal S, Karakurt Z, Harman R, Aslan E, Mutlu-Yilmaz E, Karabay O, Uygun Y, Ulug M, Tosun S, Dogru A, Sener A, Dogan M, Hasbun R, Durmus G, Turan H, Batirel A, Duygu F, Inan A, Akkoyunlu Y, Celebi G, Ersoz G, Guven T, Dagli O, Guler S, Meric-Koc M, Oncu S, Rello J (2020) Treatment of ventilator-associated pneumonia (VAP) caused by acinetobacter: results of prospective and multicenter ID-IRI study. Eur J Clin Microbiol Infect Dis 39(1):45-52. https://doi.org/10.1007/s10096-019-03691-Z

5. Joffe AR, Muscedere J, Marshall JC, Su Y, Heyland DK, Canadian Critical Care Trials Group (2008) The safety of targeted antibiotic therapy for ventilator-associated pneumonia: a multicenter observational study. J Crit Care 23(1):82-90. https://doi.org/10.1016/j.jcrc. 2007.12.006

6. Kemnic TR, Coleman M (2018) Trimethoprim sulfamethoxazole. Stat Pearls [Internet]. Stat Pearls Publishing, Treasure Island (FL)

7. Strazzulla A, Postorino MC, Purcarea A, Chakvetadze C, de Farcy de Pontfarcy A, Tebano G, Pitsch A, Vong L, Jochmans S, Vinsonneau C, Monchi M, Diamantis S (2019) Trimetoprimsulfametoxazole in ventilator-associated pneumonia: a cohort study. Eur J Clin Microbiol Infect Dis 38(11):2163-2169. https:// doi.org/10.1007/s10096-019-03656-2

8. Journal officiel de la République Française. LOI n 2012-300 du 5 mars 2012 relative aux recherches impliquant la personne humaine (1). Available at https://www.legifrance.gouv.fr/affichTexte.do? cidTexte=JORFTEXT000025441587\&categorieLien=id (French, last accessed on April $9^{\text {th }}, 2020$ )

9. Deplanque D, Sénéchal-Cohen S, Lemaire F (2017) Participants of Giens XXXII, round table n(o) 5. French Jardé's law and European regulation on drug trials: Harmonization and implementation of new rules. Thérapie. 72(1):73-80. https://doi.org/10.1016/j.therap. 2016.12.006

10. Craven DE, Hudcova J, Lei Y (2011) Diagnosis of ventilatorassociated respiratory infections (VARI): microbiologic clues for trachea bronchitis (VAT) and pneumonia (VAP). Clin Chest Med 32(3):547-557. https://doi.org/10.1016/j.ccm.2011.06.001

11. Quartin AA, Scerpella EG, Puttagunta S, Kett DH (2013) A comparison of microbiology and demographics among patients with healthcare-associated, hospital-acquired, and ventilator-associated pneumonia: a retrospective analysis of 1184 patients from a large, international study. BMC Infect Dis 13:561. https://doi.org/10. 1186/1471-2334-13-561

12. Stevens PE, Levin A (2013) Kidney disease: improving global outcomes chronic kidney disease guideline development work group members: evaluation and management of chronic kidney disease: synopsis of the kidney disease: improving global outcomes 2012 clinical practice guidelines. Ann Intern Med 158(11):825-830. https://doi.org/10.7326/0003-4819-158-11-201306040-00007

13. Hedrick TL, Smith RL, McElearney ST, Evans HL, Smith PW, Pruett TL, Young JS, Sawyer RG (2008) Differences in earlyand late-onset ventilator-associated pneumonia between surgical and trauma patients in a combined surgical or trauma intensive care unit. J Trauma 64(3):714-720. https://doi.org/10.1097/TA. 0b013e31811ec18e

14. Singer M, Deutschman CS, Seymour CW, Shankar-Hari M, Annane D, Bauer M, Bellomo R, Bernard GR, Chiche JD, Coopersmith CM, Hotchkiss RS, Levy MM, Marshall JC, Martin GS, Opal SM, Rubenfeld GD, van der Poll T, Vincent JL, Angus DC (2016) The Third International Consensus Definitions for Sepsis and Septic Shock (Sepsis-3). JAMA. 315(8):801-810. https://doi.org/10.1001/jama.2016.0287

15. Gao B, Li X, Yang F, Chen W, Zhao Y, Bai G, Zhang Z (2019) Molecular epidemiology and risk factors of ventilator-associated 
pneumonia infection caused by carbapenem-resistant enterobacteriaceae. Front Pharmacol 10:262. https://doi.org/10.3389/fphar. 2019.00262

16. Abbara S, Pitsch A, Jochmans S, Hodjat K, Cherrier P, Monchi M, Vinsonneau C, Diamantis S (2019) Impact of a multimodal strategy combining a new standard of care and restriction of carbapenems, fluoroquinolones and cephalosporins on antibiotic consumption and resistance of Pseudomonas aeruginosa in a French intensive care unit. Int J Antimicrob Agents 53(4):416-422. https://doi.org/ 10.1016/j.ijantimicag.2018.12.001

17. Li H, Yang CH, Huang LO, Cui YH, Xu D, Wu CR, Tang JG (2018) Antibiotics de-escalation in the treatment of ventilatorassociated pneumonia in trauma patients: a retrospective study on propensity score matching method. Chin Med J 131(10):11511157. https://doi.org/10.4103/0366-6999.231529

18. Khan RA, Aziz Z (2017) A retrospective study of antibiotic deescalation in patients with ventilator-associated pneumonia in Malaysia. Int J Clin Pharm 39(4):906-912. https://doi.org/10. 1007/s11096-017-0499-2

19. Eachempati SR, Hydo LJ, Shou J, Barie PS (2009) Does deescalation of antibiotic therapy for ventilator-associated pneumonia affect the likelihood of recurrent pneumonia or mortality in critically ill surgical patients? J Trauma 66(5):1343-1348. https://doi.org/ 10.1097/TA.0b013e31819dca4e

20. Giantsou E, Liratzopoulos N, Efraimidou E, Panopoulou M, Alepopoulou E, Kartali-Ktenidou S, Manolas K (2007) Deescalation therapy rates are significantly higher by bronchoalveolar lavage than by tracheal aspirate. Intensive Care Med 33(9):15331540. https://doi.org/10.1007/s00134-007-0619-x
21. Niederman MS (2006) The importance of de-escalating antimicrobial therapy in patients with ventilator-associated pneumonia. Semin Respir Crit Care Med 27(1):45-50. https://doi.org/10.1055/ s-2006-933673

22. Wood GC, Jonap BL, Maish GO 3rd, Magnotti LJ, Swanson JM, Boucher BA, Croce MA, Fabian TC (2018) Treatment of achromobacter ventilator-associated pneumonia in critically ill trauma patients. Ann Pharmacother 52(2):120-125. https://doi.org/10. 1177/1060028017730838

23. Luterbach CL, Boshe A, Henderson HI, Cober E, Richter SS, Salata RA, Kalayjian RC, Watkins RR, Hujer AM, Hujer KM, Rudin SD, Domitrovic TN, Doi Y, Kaye KS, Evans S, Fowler VG Jr, Bonomo RA, van Duin D (2018) The role of trimethoprim/sulfamethoxazole in the treatment of infections caused by carbapenem-resistant enterobacteriaceae. Open Forum Infect Dis 6(1):ofy351. https://doi. org/10.1093/ofid/ofy351

24. Eliakim-Raz N, Hellerman M, Yahav D, Cohen J, Margalit I, Fisher S, Zusman O, Shaked H, Bishara J (2017) Trimethoprim/ sulfamethoxazole versus vancomycin in the treatment of healthcare/ventilator-associated MRSA pneumonia: a case-control study. J Antimicrob Chemother 72(3):882-887. https://doi.org/10. 1093/jac/dkw510

25. El Sayed N, Ashour M, Amine AEK (2018) Vancomycin resistance among Staphylococcus aureus isolates in a rural setting. Egypt Germs 8(3):134-139. https://doi.org/10.18683/germs.2018.1140

Publisher's note Springer Nature remains neutral with regard to jurisdictional claims in published maps and institutional affiliations. 